\title{
Pelvic organ prolapse after subtotal and total hysterectomy: a long-term follow-up of an open randomised controlled multicentre study
}

Pär Persson, Jan Brynhildsen and Preben Kjölhede

\section{Linköping University Post Print}

\section{Tweet}

N.B.: When citing this work, cite the original article.

This is the pre-reviewed version of the following article:

Pär Persson, Jan Brynhildsen and Preben Kjölhede, Pelvic organ prolapse after subtotal and total hysterectomy: a long-term follow-up of an open randomised controlled multicentre study, 2013, British Journal of Obstetrics and Gynecology, (120), 12, 1556-1565.

which has been published in final form at:

http://dx.doi.org/10.1111/1471-0528.12399

Copyright: Wiley-Blackwell

http://eu.wiley.com/WileyCDA/Brand/id-35.html

Postprint available at: Linköping University Electronic Press

http://urn.kb.se/resolve?urn=urn:nbn:se:liu:diva-100471 
Main research article with the title

Pelvic organ prolapse after subtotal and total hysterectomy. A long-term

follow-up of an open randomised controlled multicentre study.

by

Pär Persson ${ }^{1}, M D, P h D$, Jan Brynhildsen ${ }^{2}$ MD PhD and Preben Kjølhede ${ }^{2}$, MD, $\mathrm{PhD}$; on behalf of the Hysterectomy Multicentre Study Group in South-East Sweden*

${ }^{1}$ Department of Women's and Children's Health, Uppsala University, S - 75185 Uppsala, Sweden

${ }^{2}$ Division of Obstetrics and Gynaecology, Department of Clinical and Experimental Medicine, Faculty of Health Sciences, Linköping University, Department of Obstetrics and Gynaecology, County Council of Östergötland, S 58185 Linköping, Sweden

(Phones: +46 1010300 00; e-mails: Jan.Brynhildsen@liu.se; Preben.Kjolhede@liu.se)

* See Acknowledgements

Corresponding author:

Pär Persson, MD, PhD

Department of Women's and Children's Health,

Uppsala University

S-751 85 Uppsala

Sweden

Phone +46 186110000

E-mail: Par.Persson@kbh.uu.se

Running title: POP after subtotal and total hysterectomy 


\section{Abstract}

Objective: To analyse the development of pelvic organ prolapse (POP) after subtotal (SH) and total hysterectomy $(\mathrm{TH})$ at long-term and to assess patient- reported symptoms regarding pelvic floor dysfunction (PFD).

Design: Long-term follow-up study of a randomised controlled multicentre study.

Setting: Seven hospitals and one private clinic in the south-east of Sweden.

Population: Of the 184 women who were eligible from the original trial 151 (82\%) responded to a postal questionnaire and $128(70 \%)$ were clinically examined.

Methods: Postal questionnaire using the short form version of Pelvic Floor Distress Inventory (PFDI-20) and clinical examination using the POP-Q system. Multivariate analyses were used.

Main outcome measures: POP-Q measurements and symptoms of PFD.

Results: Follow-up time was median 11.3 years. Less than $3 \%$ had stage 3 prolapse. No significant difference was found in presence of stage 2 or higher stage prolapse between the two hysterectomy groups (39\% in SH vs. 37\% in TH; OR 1.28 (95\%CI 0.59-2.80). Nor was there any significant difference in the quality-of-life measurement between the SH and TH groups (Summary score PFDI-20: median 93 (range 60-201) vs. 87 (range 60-186); Fishers PLSD: $\mathrm{p}=0.78$ ). None of the symptoms of PFD revealed statistically significant differences between the hysterectomy groups.

\section{Conclusion}

This long-term follow-up study of PFD showed basically no significant differences in subjective or objective measurements of POP or in pelvic floor-specific QoL aspects after SH and TH. However, due to low statistical power the results are inconclusive. Larger trials are necessary and probably also a longer follow-up period. 
Key words: Hysterectomy; Pelvic organ prolapse; Randomised trial; Long-term follow-up; POP-Q;

The study was registered in ClinicalTrial.gov Protocol Registration System (NCT00876057) with initial release 04/03/2009. 


\section{Introduction}

Hysterectomy is the most frequently performed major gynaecological intervention [1].

Subtotal hysterectomy is an option for removal of the uterus for benign gynaecologic disorders. This procedure has gained popularity among women and physicians because of reports indicating potential advantages [2-5]. It also seems to be a mode of hysterectomy that is preferred and recommended by gynaecologist to women with certain gynaecological disorders [6-8].

Relatively few randomised trials have compared subtotal abdominal hysterectomy (SH) and total abdominal hysterectomy (TH) [9-15]. In a recently updated meta-analysis no major differences have been shown in physical including urinary and bowel function, psychological or sexual outcomes between the two modes [1]. Women are more likely to experience ongoing cyclical bleeding up to a year after surgery with SH and due to the preserved cervix the women should be encouraged to continuously and regularly perform check-ups for cervical neoplasia.

The role of hysterectomy as a risk factor for post-hysterectomy pelvic organ prolapse (POP) has been discussed for many years but there is still no consensus about the role of mode of hysterectomy as etiologic factor [16]. The impact of mode of hysterectomy on the development of post-hysterectomy POP has not been well investigated. Only two of the randomised trials comparing $\mathrm{SH}$ and $\mathrm{TH}$ have focused on development of POP at long-term $[17,18]$ and both found no significant differences in outcome of POP development. POP is a common gynaecological problem with a multifactorial aetiology [19]. The pelvic floor anatomy is complex and it is important to recognize this complexity in order to understand the development of POP [20].

We have previously published a randomised trial comparing $\mathrm{SH}$ and $\mathrm{TH}$ in order to analyse short-term recovery and psychological wellbeing one year after surgery $[15,21]$. 
Based on the women participating in that randomised trial we aimed to investigate the development of POP subjectively and objectively at long term. In addition to the information such a study will provide concerning the association between mode of hysterectomy and later development of prolapse there are quality of life and health economic aspects of this issue to be considered if one of the hysterectomy methods is found to increase the risk of subsequently developing a surgery-demanding prolapse.

The aims of this study were to analyse the development of pelvic organ prolapse in SH and $\mathrm{TH}$ at long-term and to assess patient-reported symptoms regarding pelvic floor dysfunction. 


\section{Methods and Material}

This is a long-term follow-up study of the women who participated in a previously published randomised controlled open multicentre study comparing subtotal and total abdominal hysterectomy for benign gynaecological diseases $[15,21]$. The randomised study was conducted between 1998 and 2004 and the follow-up study was performed between May 2011 and April 2012.

The flow chart is shown in Figure 1. All 184 women who were operated on in the randomised trial and were alive in April 2011 were approached by mail. The letter contained a part explaining the purpose of the study including an informed consent form and a questionnaire with 33 questions dealing with symptoms of pelvic floor dysfunction (PFD). The woman was asked to answer whether she wanted to participate in the study or not. If affirmative she signed the informed consent form and returned it together with the questionnaire. A reminder was sent to the non-responders within four weeks. One hundred and sixty women answered the letter; eight of these did not want to participate at all and one wished to take part in the clinical examination only. In all 24 women did not respond. 


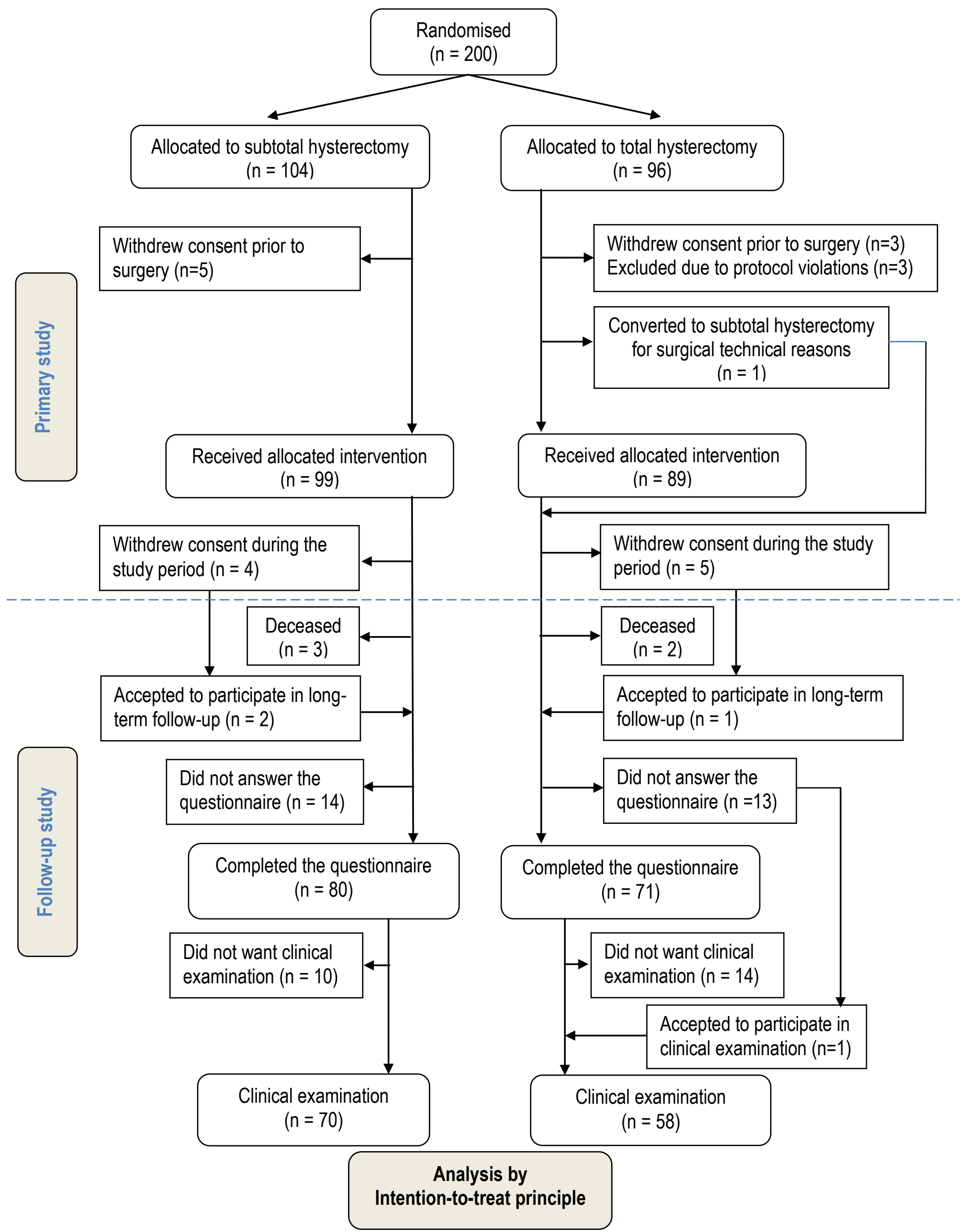

Figure 1. Flow chart at long-term follow-up. 


\section{Surgical technique of hysterectomy}

The hysterectomy was performed or supervised by a consultant and conducted under general anaesthesia. Decision of mode of skin incision transverse or low midline was made by the surgeon based on the size of the uterus and/or previous lower abdominal surgery. The surgical technique of the hysterectomy was left to the surgeon's discretion. Basically the surgical techniques of the $\mathrm{TH}$ and $\mathrm{SH}$ were carried out according to the principles described by Thompson [22] with the exception that no pelvic peritonealisation was made in either SH or TH. The sacrouterine and cardinal ligaments were anchored to the vaginal corner in $\mathrm{TH}$ whereas no plication or reinforcement of the ligaments was done in $\mathrm{SH}$.

\section{Postal questionnaire concerning PFD and quality of life ( $Q o L)$}

To assess symptoms and impact on quality of life of PFD the women completed a postal questionnaire including a modified version of the condition-specific QoL questionnaire, the short form version of Pelvic Floor Distress Inventory (PFDI-20) [23]. The PDFI-20 is a composite of three different scales: the Urinary Distress Inventory (UDI-6), the Pelvic Organ Prolapse Distress Inventory (POPDI-6), and the Colorectal-Anal Distress Inventory (CRADI8). The PFDI is a reliable and commonly used instrument in pelvic floor disorders and useful in clinical practice $[23,24]$. Furthermore it has been validated for use under Swedish circumstances [25]. In order to keep the questionnaire in a reasonable size to obtain a high response rate we excluded some questions from the PDFI-20. The excluded items were four questions from the CRADI-8 and constituted questions that more reflected other reasons than prolapse-related perceived discomfort such as functional bowel disorders, gastro intestinal diseases, dietary reasons and ano-rectal disorder. One question from the POPDI-6 was excluded as a similar question concerning digital assistance of pushing the vaginal bulge was given in the CRADI-8. Our modification of the PFDI-20 comprises the exclusion of one question in the POPDI-6 (Do you ever have to push up on a bulge in the vaginal area with your 
finger to start or complete urination?) and the four questions in the CRADI-8 ('Do you feel you need to strain too hard to have bowel movement'?; 'Do you usually have pain when you pass your stool?'; 'Do you experience a strong sense of urgency and have to rush to the bathroom to have a bowel movement?', and 'Does a part of your bowel even pass through the rectum and bulge outside during or after bowel movement? '). In addition the questionnaire contained five generic questions concerning the female genitals, five questions concerning urinary symptoms and habits, three questions concerning the impact of urinary and faecal leakage on social and daily living, and finally five questions concerning frequency of use of sanitary pads and leakage of urine, gas and loose and solid stool. In total the questionnaire thus contained 33 questions. The questions were constructed as simple sentences. Each question was answered by putting an $\mathrm{X}$ in the box that was most appropriate. The answers were given on a Likert type scale with the options 'No' (0); 'Yes, but it does not bother me at all' (1); 'Yes, and it bothers me somewhat' (2); 'Yes, it bothers me moderately' (3); and 'Yes, it bothers me quite a bit' (4). For the questions about frequency of use of sanitary pads and leakage the option of answers were operationalized to 'Daily', 'Sometimes weekly', 'Sometimes monthly', 'Sometimes yearly' or 'Never'. For each of the three scales in the PFDI the score was calculated as the mean score of the questions belonging to the scale multiplied with 25 . Thus each of the 3 scales scored from 0 (least distress) to 100 (greatest distress). The sum of the scores of these 3 scales serves as the overall summary score of the PFDI-20 and ranges from 0 $-300$.

\section{Pelvic Organ Prolapse Quantification (POP-Q)}

Prior to the hysterectomy and at the long-term follow-up the women were interviewed and clinically evaluated by the physician. Gynaecological examination was done with the woman in the dorsal lithotomy position and with an emptied bladder. The Pelvic Organ Prolapse - 
Quantification (POP-Q) classification system, as described by the International Continence Society (ICS) was used [26].

Briefly, the POP-Q considers six defined points within the vagina: two anterior (Aa and $\mathrm{Ba}$ ), two posterior (Ap and Bp) and two apical (C and D) (Fig. 2; Adapted from Digesu et al.[27]). Hymen is considered as landmark for reference. Each point is expressed as distance in centimetres from the hymen with the woman performing maximum Valsalva. Each point is defined as zero if it is seen at the level of the hymenal ring and as a negative or positive numbers if they are seen above or below the hymen, respectively. POP-Q also considers three other measurements: total vaginal length $(t v l)$, genital hiatus $(g h)$ and perineal body $(p b)$. These are expressed in centimetres and have no sign because they denote lengths and not positions relative to the hymen. $t v l$ is the greatest depth of the vagina in centimetres when $\mathrm{C}$ and $\mathrm{D}$ are reduced to its full normal position. $g h$ is measured from the middle of the external urethral meatus to the posterior midline hymen. $p b$ is measured from the posterior margin of the GH to the middle of the anal orifice. By definition the ranges of position of point Aa and Ap, respectively, relative to the hymen is -3 and $+3 \mathrm{~cm}$ and point $\mathrm{Ba}$ and $\mathrm{Bp}$, respectively, is $3 \mathrm{~cm}$ and $+t v l$. Stages of the prolapse (stage 0 to stage 4 ) are assigned according to the most severe portion when the full extent of the protrusion has been demonstrated (Fig. 3) [26].

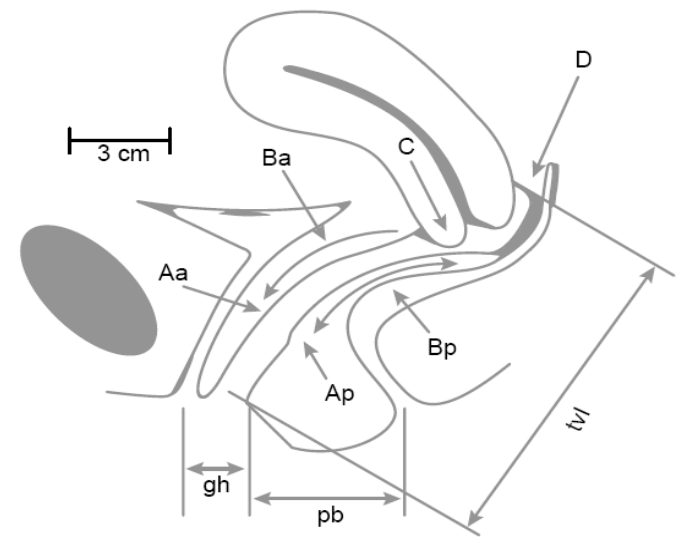

Figure 2: The POP-Q system, as described by the ICS. 


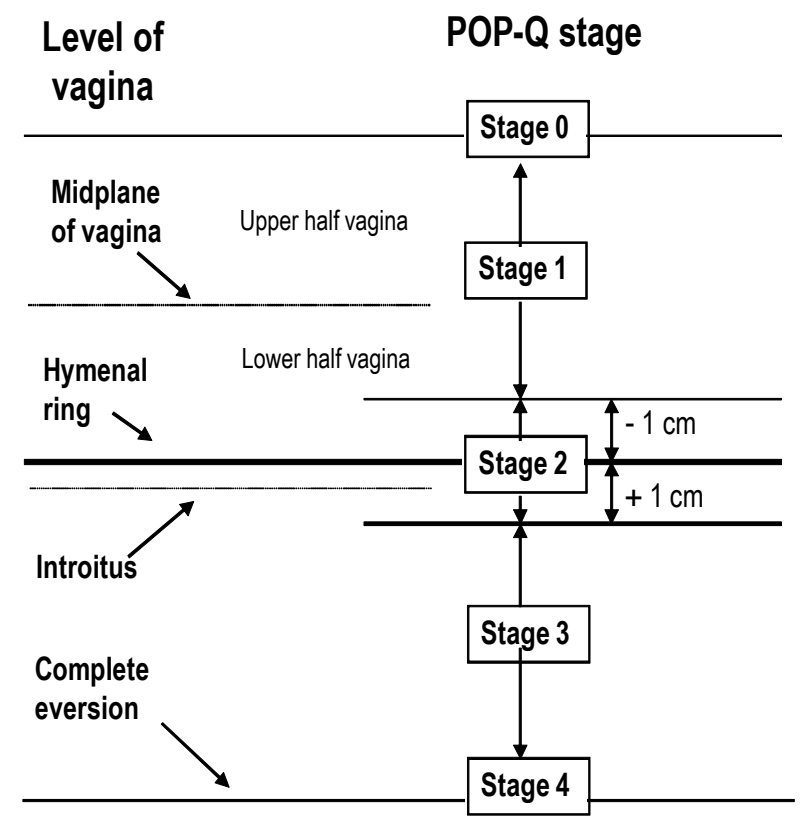

Figure 3. Quantitative staging of prolapse according to the POP-Q classification.

At the preoperative examination the POP-Q measurement included a qualitative determination only of the stage of prolapse. In the follow-up examination the POP-Q measurements were quantitative as well as qualitative. At the interviews the women were asked standardized questions about occurrence of stress urinary incontinence, urgency and urge incontinence, faecal incontinence, feeling of incomplete bladder emptying and frequency of bowel movements. Constipation was defined as bowel movements less than three times per week. At the follow-up interview additional information was obtained regarding heredity for POP surgery, previous POP and urinary incontinence surgery, current smoking habits, current age, length and weight and the birth weight of the largest baby. The patient records of those patients who had had surgery for POP or urinary incontinence in the follow-up period were 
scrutinized and information about surgical procedure and POP-Q status prior to the POP surgery was registered. The POP-Q staging measurements obtained just prior to the POP surgery were used as substitute for the measurement in the follow-up outcome in these cases. The patient records of the non-participating women were also examined in order to disclose surgery on the cervix, POP or urinary incontinence surgery.

\section{Statistics}

The data were analysed according to the "intention-to-treat" principle. Univariate analyses were performed with non-parametric statistical tests: Mann-Whitney U-test, Yates corrected $\chi^{2}$ test and Fisher's exact test as appropriate. Dependent outcome variables were evaluated by means of multiple logistic regression analyses for dichotomous nominal variables and analyses of covariance (ANCOVA) for continuous variables. The results were presented as crude and adjusted odds ratio (OR) estimates with $95 \%$ confidence intervals (CIs), or pvalues. In the multivariate models adjustments were done simultaneously for the confounding factors age, parity and BMI. Additional potential confounders may be added to the models and if so the confounders are specifically stated in the text or in the Table or Figure. The statistical analyses were performed with StatView ${ }^{\circledR}$ for Windows, Copyright $\odot$, 1992-1998, Version 5.0.1 (SAS Institute Inc., SAS Campus Drive, Cary, NC 27513, USA). 


\section{Results}

The response rate to the questionnaire was $82 \%(151 / 184)$ and the clinical examination was carried out in $70 \%(128 / 184)$. The demographic and clinical baseline data of participants and non-participants in the follow-up study are presented in Table 1. The non-participants were significantly younger than the participants; otherwise no significant differences were observed between participants and non-participants.

Demographic data of the hysterectomy groups at baseline and follow-up are shown in Table 2. The median follow-up period was 11.3 years (range 7.0 - 13.7 years). No significant differences were seen between the SH and TH groups concerning any of the demographic or clinical parameters depicted in Table 1 at the follow-up except for operating time showing significantly shorter time for the SH (data not shown).

Seven women (7\% (7/98)) in the SH group had the preserved cervix removed (9-120 months postoperatively). One woman $(1 \%(1 / 98))$ in the SH underwent prolapse surgery during the follow-up period compared with three $(3.5 \%(3 / 86))$ in the TH group (9-32 months postoperatively). Three women in each group (3.1\% (3/98) vs. 3.5\% (3/86)) had surgery for urinary incontinence (TVT) (8-120 months postoperatively) during the follow-up period.

The qualitative and quantitative POP-Q measurements are shown in Table 3 and 4, respectively. No significant differences were found in presence of stage 2 or higher stage prolapse in any of the vaginal compartments or overall between the two hysterectomy groups. The number of women with stage 3 prolapse was low (anterior compartment: $2(2.9 \%(2 / 70))$ in the SH group vs. $1(1.7 \%(1 / 58))$ in the TH group; posterior compartment: $0(0 \%(0 / 70))$ vs. $2(3.4 \%(2 / 58))$, and apical compartment: $0(0 \%(0 / 70))$ vs. $1(1.7 \%(1 / 58))$, respectively. Overall nearly $40 \%$ of the women presented with stage 2 or more prolapse. The prolapse was beyond the hymen in only four women $(9 \%$ (4/44) of those with stage 2 prolapse. Concerning the quantitative measurements (Table 4), point $\mathrm{D}$ as well as the total vaginal length were 
significantly longer in the $\mathrm{SH}$ group compared with the TH group (mean difference $1 \mathrm{~cm}$ and $0.8 \mathrm{~cm}$, respectively).

The outcome of the PFD-specific QoL instrument PFDI-20 and the subscales are presented in Figure 4. No significant differences were found in any of the QoL measurements between the $\mathrm{SH}$ and $\mathrm{TH}$ groups according to the analysis of covariance and the subsequent post hoc analysis. 


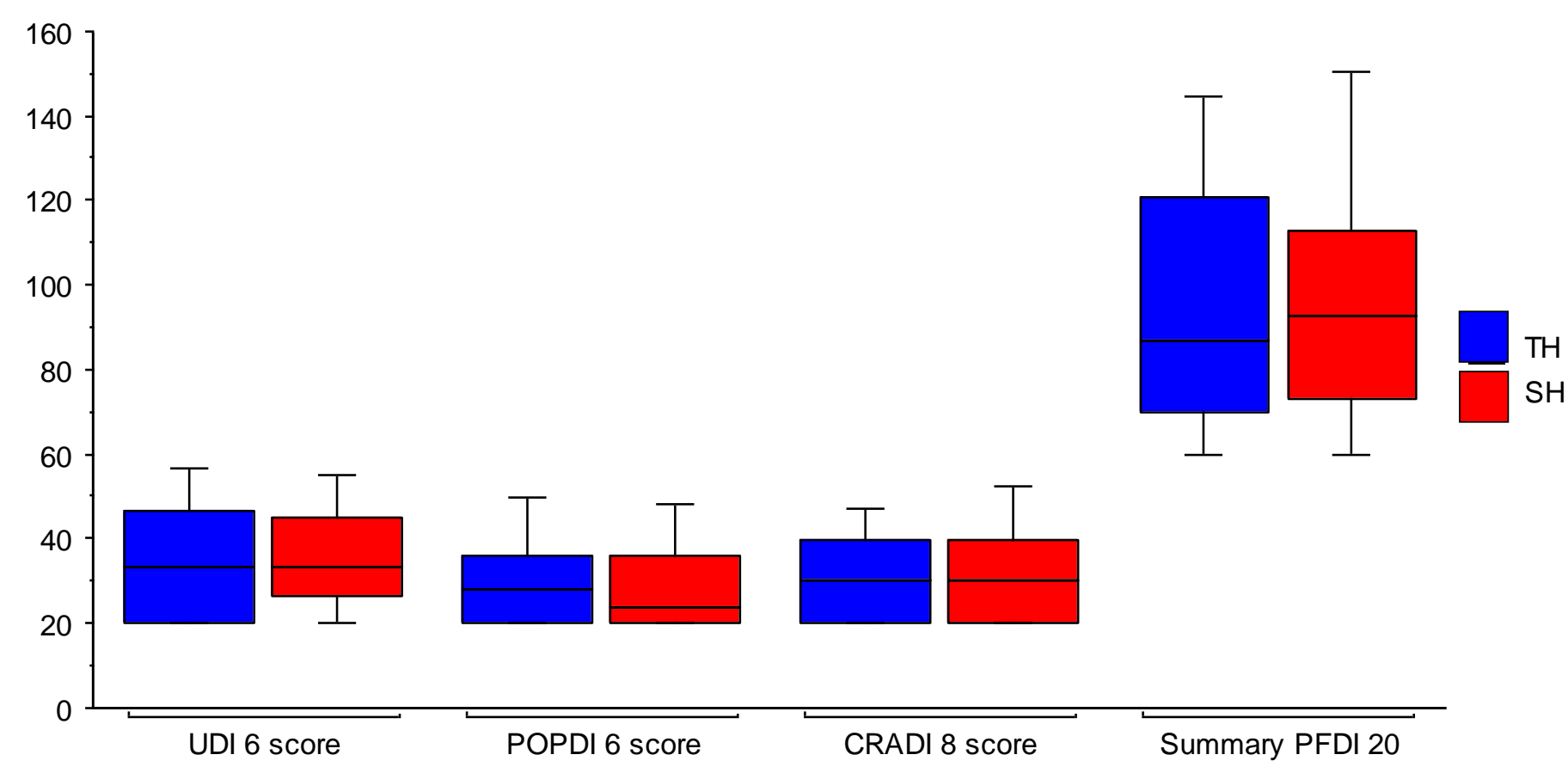

\begin{tabular}{|c|c|c|c|c|c|c|c|c|c|c|c|}
\hline \multicolumn{12}{|c|}{ Analysis of covariance } \\
\hline \multicolumn{3}{|c|}{ UDI 6} & \multicolumn{3}{|c|}{ POPDI 6} & \multicolumn{3}{|c|}{ CRADI 8} & \multicolumn{3}{|c|}{ Summary PFDI 20} \\
\hline & & $\mathrm{p}$-value & & & $p$-value & & & $\mathrm{p}$-value & & & p-value \\
\hline$F_{1,149}$ & p-value & Fisher's PLSD & $F_{1,149}$ & $p$-value & Fisher's PLSD & $F_{1,149}$ & $p$-value & Fisher's PLSD & $F_{1,149}$ & $\mathrm{p}$-value & Fisher's PLSD \\
\hline 0.439 & 0.5086 & 0.5497 & 0.036 & 0.8494 & 0.8528 & 0.133 & 0.7154 & 0.8283 & 0.136 & 0.7126 & 0.7783 \\
\hline
\end{tabular}

Adjusted for age, parity, BMI, incontinence and prolapse surgery.

Figure 4. Summary score of PFDI and the subscales median 11 years after subtotal and total hysterectomy and result of the analysis of covariance. Boxes represent median and $25-75$ per centiles. Bars represent $10-90$ per centiles. $\mathrm{TH}=$ total hysterectomy; $\mathrm{SH}=$ subtotal hysterectomy. 
Symptoms of PDF obtained at the interviews preoperatively and at the follow-up are reported in Table 5. None of the characteristics revealed statistically significant differences between the hysterectomy groups. Use of oestrogen replacement therapy (ERT) locally or systemically did not differ significantly between the $\mathrm{SH}$ and $\mathrm{TH}$ groups at the clinical followup $\left(24.3 \%(17 / 70)\right.$ vs. $15.5 \%(9 / 58), \mathrm{OR}_{\text {(adjusted for age and BMI) }} 1.76$ (95\% CI $\left.0.71-4.35\right)$. In all $27 \%(21 / 78)$ of the women in the SH group declared that they had troublesome problems with their genitals compared with $29 \%(20 / 69)$ in the TH group $\left(\mathrm{OR}_{\text {(adjusted for age, BMI, ERT, prolapse and }}\right.$ incontinence surgery) 0.96 (95\% CI 0.43-2.12).

The prevalence and frequency of urinary and anal incontinence and use of sanitary pads according to the questionnaire at the follow-up are shown in Table 6. Use of sanitary pads and loose stool incontinence revealed significance between the groups in favour of the TH group. 


\section{Discussion}

Main findings

This long-term follow-up study of PFD after subtotal and total abdominal hysterectomy showed basically no significant differences in subjective or objective measurements of POP or in pelvic floor-specific QoL aspects between modes of hysterectomy.

\section{Strengths and weaknesses}

The strengths of this study are the prospective and randomised design and the long follow-up period. Originally the power calculation was carried out for the primary outcome of the study and thus no sample size estimation has been done for this secondary study. Assuming that the difference in occurrence of prolapse of the anterior compartment between the groups $(23 \% \mathrm{vs}$. $14 \%$ ) should be significant at a $5 \%$ level with $80 \%$ power a sample size of nearly 600 individuals were needed. Thus our study as well as the other randomised long-term study of subtotal and total hysterectomy [17] presenting objective data is underpowered. Accordingly the non-significant findings in this study make the results inconclusive and consequently should be interpreted with great precaution. Another drawback of our study is the lack of pelvic floor-specific QoL assessment preoperatively. However the preoperative prevalence of prolapse and urinary incontinence were similar in the two groups. Besides we used two validated generic QoL forms (the Psychological General Well-Being and Women's Health Questionnaire) in the primary study and found no significant difference in these forms between the modes of hysterectomy on any occasion of assessment up to one year after surgery [21]. It therefore seems conceivable that even a pelvic floor-specific QoL would be similar preoperatively. At the follow-up we used a modified PFDI-20 form to measure the pelvic floor-specific QoL. We are aware of the fact that the validation of the form cannot therefore be guaranteed. However we compared the scores obtained from the same questions between the two modes of hysterectomy and found no significant difference. Thus by adding questions that to a substantial degree more may reflect other reasons than pelvic floor organ 
dysfunction seems unlikely to improve the chance to detect a difference in pelvic floorspecific QoL.

\section{Interpretation}

In a meta-analysis of studies of SH and TH Gimbel stated that prolapse formation and urinary incontinence were more often associated with SH than TH [28,29]. Most studies in the metaanalysis were observational and the results of the two randomised trials that were included did not support the conclusion. The follow-up period was relatively short (one year) or not mentioned and the prolapse identification was not based on clinical examination but based on a questionnaire. Only two randomised trials of SH and $\mathrm{TH}$ have presented long-term followup data concerning PFD $[17,18]$. Both of these studies conclude that there were no major long-term differences in outcome after SH and TH. However, these studies have substantial restrictions. The study by Greer et al. had a low number of participants, only 37 of the 135 randomised in the original study, and presented only subjective data obtained from a questionnaire [18]. The study by Thakar et al. [17] suffered from a relatively low response rate $(65 \%)$ and the clinical examination was conducted in less than $50 \%$ of the randomised women. By contrast our study had a response rate of $82 \%$ and $70 \%$ of the randomised women were clinically examined.

In common with the findings of Thakar et al. [17] we found no significant differences in POP-Q staging between the groups, but the prevalence of significant prolapse ( $\geq$ stage 2$)$ in our study was substantially higher than that reported by Thakar. The same quantification system was used to assess the prolapse. It may be difficult to explain the difference. Whether it depends on simple selection bias, differences in surgical technique causing different outcome or truly a difference in English and Swedish populations remains unresolved. We found a considerable difference in location of the prolapse component with the highest prevalence of prolapse in the posterior compartment equally distributed between women in 
the $\mathrm{SH}$ and $\mathrm{TH}$ groups. In contrast with that finding, prolapse in the anterior compartment occurred with an odds ratio in the SH group more than twice that in the TH group. Based on our findings it seems reasonable to present data for each compartment as the impact of hysterectomy theoretically may influence each compartment differently.

Women that are operated on for genital prolapse are on average in the sixth decade of life. The mean age at follow-up of the women in the Thakar study [17] was about 53 years and in our study 57 years. Thus the higher prevalence in our study could reflect an effect of age and the possibility of having developed a prolapse due to tissue factors and aging. The follow-up period may indeed be too short even in our study in order to show a significant difference in occurrence of prolapse between the two groups. In women without POP at the time of hysterectomy Dällenback et al. found a cumulative risk for pelvic repair surgery after hysterectomy in about $1 \%$ after 15 years [16]. Even though $38 \%$ of the women in our study had prolapse $\geq$ stage 2 it must be emphasised that the prevalence of women with a prolapse beyond the level of the hymen was less than 5\% indicating that the vast majority had very small prolapse.

Women who had subtotal hysterectomy used significantly more often sanitary pads median 11 years after the hysterectomy than the women who had a total hysterectomy. The clinical impact of this is uncertain but might reflect a drawback of the subtotal hysterectomy giving more periodic bleedings and vaginal discharge and therefore requiring the woman to use sanitary pads even after menopause.

Analogous with the findings by Greer and Thakar we found no significant difference in occurrence of urinary or faecal incontinence, feeling of incomplete bladder emptying or constipation between women who had SH and TH. The pelvic floor-specific QoL assessments in the present study revealed no difference between the groups. Although the American and English long-term follow-up studies did not use pelvic floor-specific QoL forms they found 
no difference between groups in health related quality of life (HRQoL) using the SF-36 which is a widely used generic HRQoL measure.

Occurrence of symptoms of urinary dysfunction seems to be in agreement between our study and the English whereas the prevalence of the bowel symptoms differs substantially. Whether this phenomenon reflects a true difference in the two populations or is a matter of cultural, dietary or functional differences is speculative.

In conclusion the results are inconclusive due to lack of statistical power. However, although we found no significant differences in symptoms of PFD or in POP, interestingly almost all odds ratios in the comparisons between the two groups were unanimously in favour of total hysterectomy. This might indicate that $\mathrm{SH}$ actually affects pelvic floor function more adversely that TH. Sufficiently powered randomised trials or meta-analysis of randomised long-term follow-up studies are needed to clarify the impact of subtotal and total hysterectomy on pelvic floor function. 


\section{Acknowledgements}

In addition to the main authors of the manuscript the "Hysterectomy Multicentre Study Group in South East Sweden" consisted of the gynaecologists Laila Falknäs MD, Ryhov Central Hospital, Jönköping; Johan Holmberg, MD, the County hospital, Eksjö; Christina Gunnervik MD, the County Hospital Värnamo; Margareta Lindvall MD, the Central Hospital, Kalmar; Tanja Konstantinova, MD, Vrinnevi Central Hospital, Norrköping; Anna Saland MD, the County Hospital, Motala and Fatma Bäckman MD, the University Hospital, Örebro.

\section{Disclosure of interests}

None of the authors or study group reports any conflicts of interest concerning this paper.

\section{Contribution to authorship}

PP and PK planned the study and wrote the manuscript. PP, JB and PK collaborated in the clinical follow-up and analysed the data. All the authors revised the paper and have seen and approved the final version.

\section{Details of ethical approval}

The study was approved by the Research Ethical Board in Linköping (Dnr 2011/50-31).

\section{Funding}

The study was financially supported by grants from the Medical Research Council of South East Sweden, the County Council of Östergötland and Linköping University 


\section{References.}

1. Lethaby A, Mukhopadhyay A, Naik R. Total versus subtotal hysterectomy for benign gynaecological conditions. Cochrane Database Syst Rev. 2012 Apr 18;4:CD004993. 169.

2. Zussman L, Zussman S, Sunley R, Bjornson E. Sexual response after hysterectomyoophorectomy: recent studies and reconsideration of psychogenesis. Am J Obstet Gynecol 1981;140:725-9.

3. Kilkku P. Supravaginal uterine amputation vs. hysterectomy. Effects on coital frequency and dyspareunia. Acta Obstet Gynecol Scand. 1983;62(2):141-5.

4. Kilkku P, Hirvonen T, Rauramo L. Supravaginal uterine amputation vs. hysterectomy. Effects on libido and orgasm. Acta Obstet Gynecol Scand. 1983;62(2):147-52.

5. Helström L. Sexuality after hysterectomy. A model based an quantitative and qualitative analyses of 104 women before and after subtotal hysterectomy. J Psychosom Obstet Gynecol 1994;15:219-29.

6. Persson P, Hellborg T, Brynhildsen J, Fredriksson M, Kjølhede P. Attitudes to mode of hysterectomy- a survey-based study among Swedish gynaecologists. Acta Obstet Gynecol Scand. 2009;88(3):267-74.

7. Gimbel H, Ottesen B, Tabor A. Danish gynecologists' opinion about hysterectomy on benign indication: results of a survey. Acta Obstet Gynecol Scand. 2002;81:1123-31.

8. David M, Wild D, Wernecke KD, Siedentopf F. Attitudes toward mode of hysterectomy: a survey-based study among German gynecologists. Eur J Obstet Gynecol Reprod Biol. 2012;164(2):216-20.

9. Thakar R, Ayers S, Clarkson P, Stanton S, Mayonda I. Outcomes after total versus subtotal abdominal hysterectomy. N Eng J Med. 2002;347(17):1318-25. 
10. Learman LA, Summitt RL Jr, Varner RE, McNeeley SG, Goodman-Gruen D, Richter HE, et al. A randomized comparison of total or supracervical hysterectomy: surgical complications and clinical outcomes. Obstet Gynecol 2003;102(3):453-62.

11. Gimbel H, Zobbe V, Andersen BA, Filtenborg T, Gluud C, Tabor A. Randomised controlled trial of total compared with subtotal hysterectomy with one-year follow up results. BJOG 2003;110(12):1088-98.

12. Gorlero F, Lijoi D, Biamonti M, Lorenzi P, Pullè A, Dellacasa I, et al. Hysterectomy and women satisfaction: total versus subtotal technique. Arch Gynecol Obstet. 2008;278(5):405-10.

13. Ellström Engh MA, Jerhamre K, Junskog K. A randomised trial comparing changes in sexual health and psychological well-being after subtotal and total hysterectomies. Acta Obstet Gynecol Scand. 2010;89(1):65-70.

14. Asnafi N, Basirat Z, Hajian-Tilaki KO. Outcomes of total versus subtotal abdominal hysterectomy. East Mediterr Health J. 2010;16(2):176-9.

15. Persson P, Brynhildsen J, Kjølhede P; Hysterectomy Multicentre Study Group in SouthEast Sweden. Short-term recovery after subtotal and total abdominal hysterectomy--a randomised clinical trial. BJOG. 2010;117(4):469-78.

16. Dällenbach P, Kaelin-Gambirasio I, Dubuisson JB, Boulvain M. Risk factors for pelvic organ prolapse repair after hysterectomy. Obstet Gynecol. 2007;110(3):625-32.

17. Thakar R, Ayers S, Srivastava R, Manyonda I. Removing the cervix at hysterectomy: an unnecessary intervention? Obstet Gynecol. 2008;112(6):1262-9.

18. Greer WJ, Richter HE, Wheeler TL, Varner RE, Szychowski JM, Kuppermann M, et al. Long-Term Outcomes of the Total or Supracervical Hysterectomy (TOSH) Trial. Female Pelvic Med Reconstr Surg. 2010;16(1):49-57.

19. Weber AM, Richter HE. Pelvic organ prolapse. Obstet Gynecol. 2005;106(3):615-34. 
20. DeLancey JO. Structural anatomy of the posterior pelvic compartment as it relates to rectocele. Am J Obstet Gynecol. 1999;180(4):815-23.

21. Persson P, Brynhildsen J, Kjølhede P; Hysterectomy Multicentre Study Group in SouthEast Sweden. A 1-year follow up of psychological wellbeing after subtotal and total hysterectomy--a randomised study. BJOG. 2010;117(4):479-87.

22. Thomson JD. Hysterectomy In: Thomson J, Rock J, editors. Te Lindes's Operative Gynecology. 7th edn. Philadelphia. J.B. Lippincott Company, 1992. 687-706.

23. Barber MD, Walters MD, Bump RC. Short forms of two condition-specific quality-oflife questionnaires for women with pelvic floor disorders (PFDI-20 and PFIQ-7). Am J Obstet Gynecol. 2005;193(1):103-13.

24. Barber MD, Chen Z, Lukacz E, Markland A, Wai C, Brubaker Let al. Further validation of the short form versions of the Pelvic Floor Distress Inventory (PFDI) and Pelvic Floor Impact Questionnaire (PFIQ). Neurourol Urodyn. 2011;30(4):541-6.

25. Teleman P, Stenzelius K, Iorizzo L, Jakobsson U. Validation of the Swedish short forms of the Pelvic Floor Impact Questionnaire (PFIQ-7), Pelvic Floor Distress Inventory (PFDI-20) and Pelvic Organ Prolapse/Urinary Incontinence Sexual Questionnaire (PISQ-12). Acta Obstet Gynecol Scand. 2011;90(5):483-7.

26. Bump RC, Mattiasson A, Bø K, Brubaker LP, DeLancey JO, Klarskov P, et al. The standardization of terminology of female pelvic organ prolapse and pelvic floor dysfunction. Am J Obstet Gynecol 1996;175:10-7.

27. Digesu GA, Chaliha C, Salvatore S, Hutchings A, Khullar V. The relationship of vaginal prolapse severity to symptoms and quality of life. BJOG. 2005;112(7):971-6.

28. Gimbel H. Total or subtotal hysterectomy for benign uterine diseases? A meta-analysis. Acta Obstet Gynecol Scand. 2007;86(2):133-44. 
29. Gimbel H, Zobbe V, Andersen BJ, Sørensen HC, Toftager-Larsen K, Sidenius K, et al. Lower urinary tract symptoms after total and subtotal hysterectomy: results of a randomized controlled trial. Int Urogynecol J Pelvic Floor Dysfunct. 2005;16(4):25762. 
Table 1. Baseline data of participants and non-participants.

\begin{tabular}{|c|c|c|c|}
\hline & $\begin{array}{c}\text { Participants } \\
(n=151)\end{array}$ & $\begin{array}{c}\text { Non-participants } \\
(\mathrm{n}=33)\end{array}$ & $p$-value* \\
\hline Age (years) & $46.2(5.2)$ & $43.4(5.1)$ & 0.0021 \\
\hline Parity & $2.1(1.0)$ & $2.1(1.4)$ & 0.5031 \\
\hline $\mathrm{BMI}\left(\mathrm{kg} / \mathrm{m}^{2}\right)$ & $25.5(3.9)$ & $26.5(4.2)$ & 0.1959 \\
\hline Smokers & $39 \quad(26 \%)$ & $13 \quad(39 \%)$ & 0.1827 \\
\hline Follow-up time (years) & $10.8(1.7)$ & $10.4(2.0)$ & 0.3055 \\
\hline \multicolumn{4}{|l|}{ Indication for hysterectomy: } \\
\hline Bleeding disturbances & $107(71 \%)$ & $24(73 \%)$ & \multirow{3}{*}{0.9736} \\
\hline Mechanical symptoms & $30 \quad(20 \%)$ & $6 \quad(18 \%)$ & \\
\hline Dysmenorrhea/endometriosis/pelvic pain & $14 \quad(9 \%)$ & $3 \quad(9 \%)$ & \\
\hline \multicolumn{4}{|l|}{ Mode of hysterectomy: } \\
\hline Subtotal hysterectomy & $80(53 \%)$ & $18(55 \%)$ & \multirow{2}{*}{0.9999} \\
\hline Total hysterectomy & $71(47 \%)$ & $15(45 \%)$ & \\
\hline \multicolumn{4}{|l|}{ Occurrence of prolapse before hysterectomy: } \\
\hline Anterior wall ( $\geq$ Stage 2) & $1(0.7 \%)$ & $0 \quad(0 \%)$ & 0.9999 \\
\hline Posterior wall ( $\geq$ Stage 2) & $1(0.7 \%)$ & $0 \quad(0 \%)$ & 0.9999 \\
\hline Apical ( $\geq$ Stage 2) & $0 \quad(0 \%)$ & $0 \quad(0 \%)$ & 1.0000 \\
\hline \multicolumn{4}{|l|}{ Symptoms of pelvic floor dysfunction ${ }^{\dagger}$ : } \\
\hline Stress urinary incontinence & $35(23 \%)$ & $5 \quad(15 \%)$ & 0.4355 \\
\hline Urgency and urge incontinence & $15(10 \%)$ & $4 \quad(12 \%)$ & 0.7524 \\
\hline Incomplete bladder emptying & $10(7 \%)$ & $1(3 \%)$ & 0.6919 \\
\hline Incontinence of stools & $0 \quad(0 \%)$ & $0 \quad(0 \%)$ & 1.0000 \\
\hline & $(n=132)$ & $(n=28)$ & \\
\hline Constipation (< 3 bowel movements per week) & $8(6 \%)$ & $2(7 \%)$ & 0.6876 \\
\hline Bowel movements per week (number) & $7.1(2.9)$ & $7.6(5.1)$ & 0.8072 \\
\hline
\end{tabular}

Figures denote mean and one standard deviation or number and per cent.

$\mathrm{BMI}=$ body mass index EBV = estimated bleeding volume peroperatively

* Mann-Whitney U-test, Yates corrected $\chi^{2}$ test and Fisher's exact test as appropriate $\dagger$ Frequency of the symptom once a month or more often. 
Table 2. Demographic and clinical data on different occasions for participants in the study

\begin{tabular}{|c|c|c|c|c|c|c|c|c|c|}
\hline & \multicolumn{9}{|c|}{ Occasion of evaluation } \\
\hline & \multicolumn{3}{|c|}{ Baseline at hysterectomy } & \multicolumn{3}{|c|}{ At follow-up questionnaire } & \multicolumn{3}{|c|}{ At follow-up clinical examination } \\
\hline & $\begin{array}{l}\text { SH group } \\
(n=98)\end{array}$ & $\begin{array}{l}\text { TH group } \\
(n=86)\end{array}$ & $p$-value ${ }^{*}$ & $\begin{array}{l}\text { SH group } \\
(n=80)\end{array}$ & $\begin{array}{c}\text { TH group } \\
(n=71)\end{array}$ & p-value* & $\begin{array}{l}\text { SH group } \\
(n=70)\end{array}$ & $\begin{array}{c}\text { TH group } \\
(n=58)\end{array}$ & $p$-value* \\
\hline Age (years) & $45.5(5.3)$ & $45.8(5.2)$ & 0.7682 & $56.9(5.6)$ & $57.1(5.3)$ & 0.8492 & $56.4(5.6)$ & $57.2(5.6)$ & 0.5266 \\
\hline $\mathrm{BMI}\left(\mathrm{kg} / \mathrm{m}^{2}\right)$ & $25.6(3.7)$ & $25.8(4.3)$ & 0.8244 & $26.6(3.9)$ & $27.1(4.6)$ & 0.4037 & $26.8(4.0)$ & $27.2(4.9)$ & 0.5853 \\
\hline Parity & $2.2(1.1)$ & $2.1(1.1)$ & 0.2725 & $2.2(1.0)$ & $2.1(1.0)$ & 0.3088 & $2.2(1.0)$ & $2.2(1.0)$ & 0.6962 \\
\hline Follow-up period (years) & ---- & ---- & & $10.8(1.6)$ & $10.8(1.7)$ & 0.9524 & $10.7(1.7)$ & $10.8(1.8)$ & 0.9633 \\
\hline
\end{tabular}

Figures denote mean and one standard deviation or number and per cent.

$\mathrm{BMI}=$ body mass index; NA = not applicable or no data available; $\mathrm{SD}=$ standard deviation; $\mathrm{SH}=$ subtotal hysterectomy; $\mathrm{TH}=$ total hysterectomy

* Mann-Whitney U-test. ** Yates corrected $\chi^{2}$-test 
Table 3. POP-Q measurements and occurrence of pelvic organ prolapse preoperatively and median 11 years after abdominal subtotal and total hysterectomy.

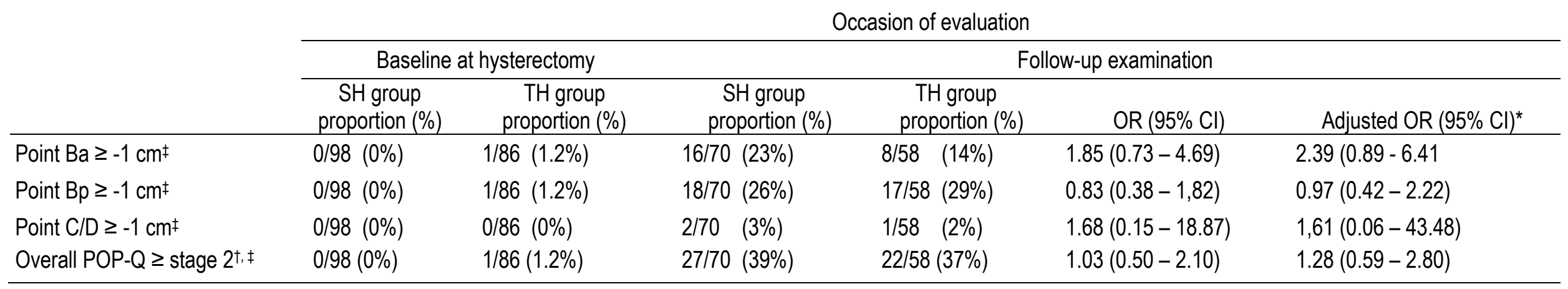

$\mathrm{BMI}=$ body mass index; $\mathrm{CI}=$ confidence interval; $\mathrm{OR}=$ odds ratio; $\mathrm{SH}=$ subtotal hysterectomy; $\mathrm{TH}=$ total hysterectomy

$\$$ Adjusted to the pre POP surgery POP-Q stage for those who had POP surgery.

* Adjusted for age, parity, BMI, mode of delivery: Caesarean section only, and birth weight of heaviest baby delivered

$\uparrow$ Overall POP- Q $\geq$ stage $2=$ at least one compartment with stage 2 or higher stage. 
Table 4. POP-Q measurements ${ }^{\ddagger}$ at follow-up median 11 years after subtotal and total hysterectomy.

\begin{tabular}{|c|c|c|c|c|c|c|c|}
\hline & \multicolumn{2}{|c|}{$\begin{array}{c}\mathrm{SH} \text { group } \\
(\mathrm{n}=70)\end{array}$} & \multicolumn{2}{|c|}{$\begin{array}{l}\text { TH group } \\
(n=58)\end{array}$} & \multicolumn{2}{|c|}{ Analysis of covariance* } & \multirow{2}{*}{$\begin{array}{l}\text { Post hoc test } \\
\text { Fisher's PLSD } \\
p \text {-value }\end{array}$} \\
\hline & median & range & median & range & $\mathrm{F}_{1,126}$-value & $p$-value & \\
\hline Point Aa (cm) & -2.5 & $-3.0-2.0$ & -2.0 & $-3.0-0$ & 0.369 & 0.5449 & 0.5313 \\
\hline Point Ba (cm) & -2.3 & $-3.0-2.0$ & -2.0 & $-3.0-0$ & 0.929 & 0.3372 & 0.3457 \\
\hline Point Ap (cm) & -2.5 & $-3.0-1.0$ & -2.0 & $-3.0-0$ & 0.261 & 0.6102 & 0.5793 \\
\hline Point Bp (cm) & -2.5 & $-3.0-1.0$ & -2.0 & $-3.0-0.5$ & 0.018 & 0.8936 & 0.9231 \\
\hline Point C (cm) & -7.0 & $-11.0--0.5$ & --- & --- & NA & NA & NA \\
\hline Point D (cm) & -8.0 & $-12.0--5.0$ & -7.0 & $-9.0--5.0$ & 19.385 & $<0.0001$ & $<0.0001$ \\
\hline $\mathrm{TVL}(\mathrm{cm})$ & 9.0 & $6.0-13.0$ & 9.0 & $6.0-11.0$ & 11.716 & 0.0009 & 0.0008 \\
\hline
\end{tabular}

$\mathrm{ERT}=$ oestrogen replacement therapy; $\mathrm{NA}=$ not applicable; PLSD $=$ protected least squared difference; $\mathrm{SH}=$ subtotal hysterectomy; $\mathrm{TH}=$ total hysterectomy; $\mathrm{TVL}=$ total vaginal length . t De facto measurements.

* Adjusted for age, parity, BMI, current smoking habits, use of ERT, surgery for prolapse and cervix extirpation. 
Table 5. Symptoms of pelvic floor dysfunction occurring with a frequency once monthly or more often reported by the women at the interview preoperatively and at the follow-up examination

Occasion of evaluation

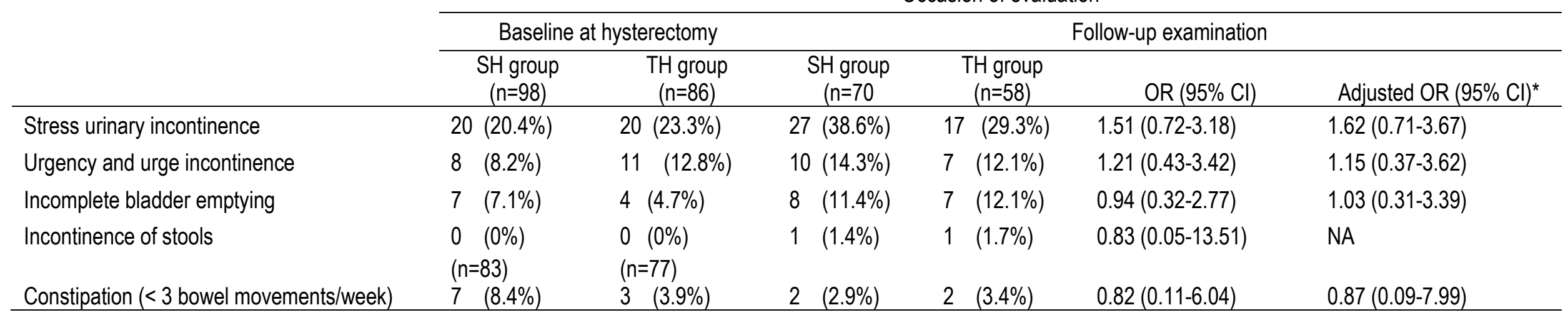

* Adjusted for age, parity, BMI, mode of delivery: Caesarean section only, birth weight of heaviest baby delivered and preoperative symptom. The urinary irritative and incontinence symptoms were also adjusted for occurrence of incontinence surgery and use of ERT. Incomplete bladder emptying and constipation were likewise adjusted for occurrence of prolapse surgery. 
Table 6. Results from the questionnaire concerning the frequency of use of sanitary pads, urinary and faecal incontinence.

$\begin{array}{llrr}\begin{array}{c}\text { SH group } \\ \text { number and }(\%)\end{array} & \begin{array}{c}\text { TH group } \\ \text { number and }(\%)\end{array} & \text { OR }(95 \% \mathrm{Cl}) & \begin{array}{c}\text { Adjusted OR } \\ (95 \% \mathrm{Cl})^{*}\end{array} \\ 53(69 \%) & 58(83 \%) & & \\ 24(31 \%) & 12(17 \%) & 2.19(1.00-4.81) & 2.75(1.15-6.54) \\ 44(55 \%) & 43(61 \%) & & \\ 36(45 \%) & 28(39 \%) & 1.26(0.66-2.40) & 1.48(0.73-2.98)\end{array}$

Gas incontinence:

$\begin{array}{lllll}\text { Never or less than monthly } & 47(59 \%) & 43(61 \%) & 1.05(0.54-2.01) & 1.13(0.58-2.20) \\ \text { Monthly or more often } & 32(41 \%) & 28(39 \%) & \end{array}$

Solid stool incontinence:

Never or less than monthly $\quad 66(83 \%) \quad 59(83 \%)$

Monthly or more often $14(18 \%) \quad 12(17 \%)$

$1.04(0.45-2.43) \quad 1.33(0.53-3.34)$

*Adjusted for age, parity and BMI. Urinary incontinence also adjusted for incontinence and POP surgery; anal incontinence for prolapse surgery, and use of sanitary pads for incontinence and POP surgery, and extirpation of cervix. 